Gut, 1979, 20, 107-113

\title{
Intestinal absorption under the influence of vasopressin: studies in unanaesthetised rats $^{1}$
}

\author{
R. DENNHARDT, B. LINGELBACH, AND F. J. HABERICH \\ From the Institut für Angewandte Physiologie der Phillpps-Universität, Marburg, Germany
}

SUMMARY Experiments were carried out in different segments of the intestine of unanaesthetised rats to assess the effect of vasopressin on intestinal absorptive processes. The following data were observed. (1) Within a physiological range of doses (Aziz, 1969), ADH diminished the net sodium absorption mainly by reducing the unidirectional sodium influx, whereas the behaviour of the efflux was not uniform. (2) The unidirectional volume fluxes showed the same behaviour as did the sodium fluxes. (3) ADH produced an oral-aboral gradient (jejunum > ileum > colon). (4) ADH did not significantly change the transfer of actively transported sugars; it did influence, however, passively transported substances. (5) During the intravenous application of $\mathrm{ADH}$, a substance was secreted into the perfusion solution which diminished the absorption of volume and electrolytes. (6) Cyclic AMP acted on intestinal absorption in the same way as did ADH. In view of these results two mutually independent transport pathways for sodium and water are supposed, one of which is influenced by ADH or cAMP. Based on a two membrane model, an ADH mechanism is discussed: the permeability of the luminal membrane system is enhanced in the presence of vasopressin.

Vasopressin, the antidiuretic agent of the neurohypophysis, changes the permeability of several epithelial structures, including the intestinal mucosa, and possibly controls the transport mechanism and permeability of such boundaries. This was shown by physiological doses applied to the small intestine of man (Soergel et al., 1968) and rats (Dennhardt and Haberich, 1972). These doses produced a decrease of both the net sodium and the net water transport. The kind of effect that was produced by ADH on the intestinal membrane structures, however, remained unclear.

In the present series of experiments on intestinal segments we examined the influence of ADH upon the unidirectional fluxes of sodium and water, as well as the transport rates of glucose, fructose, 3-0-methyl-glucose, and urea. For this purpose, we had to work out an experimental procedure which allowed experiments on unanaesthetised rats because it is well known that anaesthetics enhance endogenous vasopressin levels (Bonjour and Malvin, 1970).

\footnotetext{
${ }^{1}$ Part of this work was reported at the 41st Meeting of the Deutsche Physiologische Gesellschaft, March 1973.

Received for publication 25 July 1978
}

\section{Methods}

The experiments were carried out on intestinal segments of the jejunum and the colon of Wistar II rats weighing between 200 and $250 \mathrm{~g}$. The animals were operated on at least three days before the beginning of the experiments. An inflatable cuff was placed at each end of a chosen intestinal segment, so that a particular intestinal segment of about $10 \mathrm{~cm}$ in length could be temporarily isolated and subsequently perfused by means of a tube placed at the proximal end and an outlet tube anastomosed to the distal end of the gut segment. All tubes came out on the animal's back and were protected by a semicircular piece of metal. The chosen intestinal segment was perfused by means of a peristaltic pump (Harvard Corp.) under recirculation conditions ('closed system'). Figure 1 illustrates the experimental procedure when the colon of the rat was perfused; in this instance only one cuff was needed. The hydrostatic pressure differences produced by fluid absorption or secretion were recorded by a pressure transducer over a period of 60 minutes; the slope of the resulting line represents the net volume changes.

To perform experiments under steady state conditions it is necessary to use the so-called 'open perfusion system'. During these experiments the 


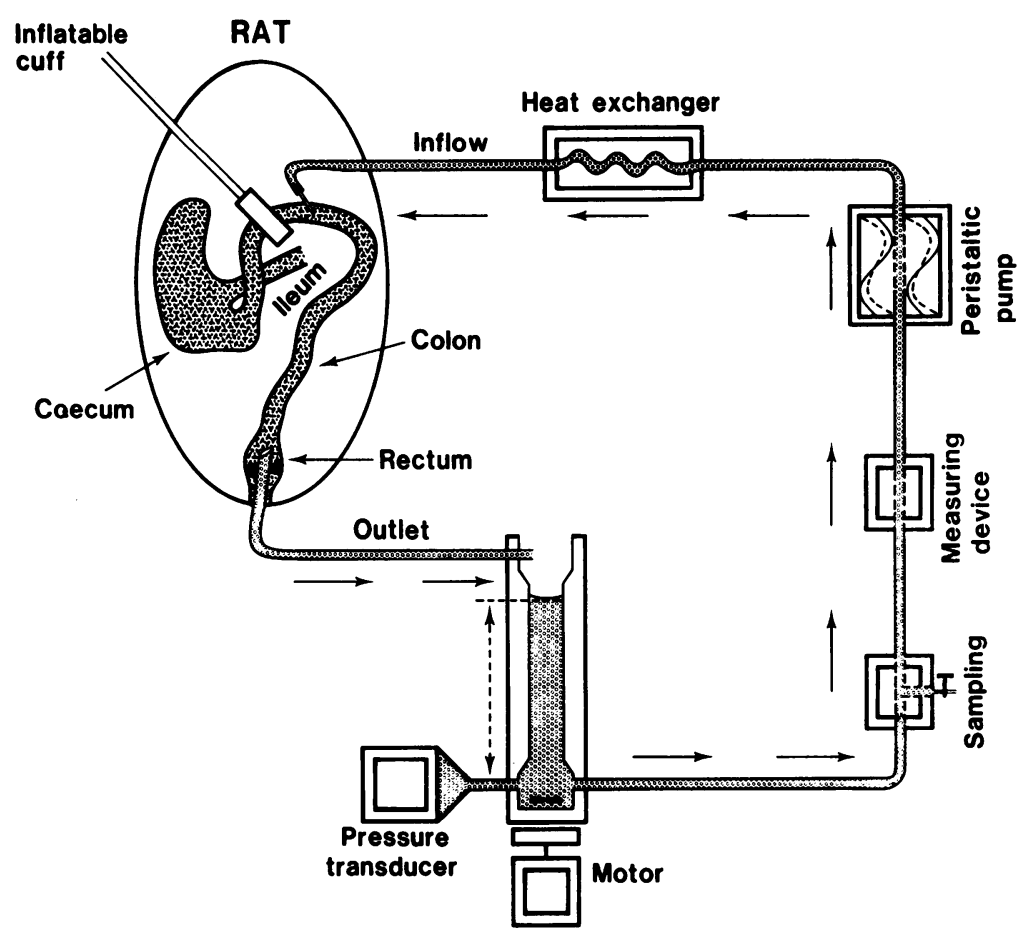

Fig. 1 Illustration of experimental procedures for perfusion of rat's colon in a recirculating system ('closed system'). The hydrostatic pressure $\mathrm{pH}$ corresponds to the whole volume in the system. Changes in net volume fluxes are recorded by pressure transducer.

differences in weight of the inflowing perfusion solution and the outflowing perfusate are determined on a special balance. This difference is equivalent to the net volume flux and can be registered continuously as a weight by a micro force transducer, arranged in parallel, which is connected to an amplifier and a recorder (Haberich et al., 1968).

The intravenous infusion rate of vasopressin was $70 \mu \mathrm{U} / \mathrm{min} \cdot 100 \mathrm{~g}$ body weight. This gave an amount that corresponded to the endogenous ADH level in rats kept thirsty over 24 hours (Aziz, 1969). It must be stressed that control experiments were carried out either before or after the ADH experiment. The effects produced by vasopressin were completely reversible after a latency period of about 40 to 60 minutes.

The question arises, as to whether this dose range affects mucosal vascular supply or intestinal motility. We measured only the pressures in the portal vein, which, however, showed no significant differences in our ADH experiments. The motility of the intestinal segment could be followed by our measuring device and neither the frequency nor the amplitude of the peristaltic waves changed compared with the control experiments.

To examine the possible 'humoral transmission' of the effect of $\mathrm{ADH}$, the following experimental procedure was chosen: after experiments with different rats in the 'closed system', the perfusate, obtained after intravenous application of ADH, was collected and perfused through an intestinal segment of another normally hydrated animal under the conditions of the 'open system'. This was followed by a control experiment or experiments, and then by a perfusion experiment with the perfusate obtained after application of ADH.

The $\mathrm{Na}^{+}$-and $\mathrm{K}^{+}$-concentrations were determined by flame photometry (I. L. Instruments), and the $\mathrm{Cl}^{-}$-concentration by coulometry (Marius). The unidirectional fluxes were measured using marked substrates. The activity of ${ }^{22} \mathrm{Na}$ was $20 \mu \mathrm{Ci} / 1$, that of ${ }^{3} \mathrm{H}$ was $500 \mu \mathrm{Ci} / \mathrm{l}$. The radio isotopes were products of Amersham Buchler (Braunschweig/ Germany). The samples $(50 \mu \mathrm{l})$ were added to a scintillation cocktail (5.5 g of a mixture of 2, 5-diphenyloxazole $(91 \%)$ and p-bis-(0-methylstyryl)-benzene $(9 \%)$ dissolved in $1 \mathrm{l}$ of toluene). For aqueous samples $15 \mathrm{ml} / \mathrm{l}$ of a solvent (Bisolv, Beckman Instruments) was added to the cocktail. The radioactivity was measured by a liquid scintillation counter (type LS 150, Beckman Instruments). The calculation of influx, efflux, and net flux from the 
experiments in the 'closed system' was performed according to the formulae described in the Appendix.

The statistical significance of differences between the controls and the ADH groups was calculated by Student's $t$ test for paired comparisons. All data were expressed as means $\pm \mathrm{SD}$.

\section{Results}

\section{ADH-EFFECT IN COLON}

Figure 2 shows the changes of sodium and chloride absorption in the colon of unanaesthetised rats after intravenous infusion of ADH in the 'closed system'. Single experiments are shown using perfusion solutions with $0.9 \%, 0.45 \%$, and $1.2 \% \mathrm{NaCl}$. ADH produces for both sodium and chloride a highly significant decrease of the net flux from lumen to blood. The absorbed amounts of chloride are higher than the corresponding amounts of sodium. This fact may be attributed to a greater potential difference at the mucosal layer which would favour the chloride flux.

Statistical interpretation shows for both parameters a highly significant decrease of net absorption under the infiuence of ADH $(\mathrm{P}<0.0001)$. The changes of volume absorption in the colon correspond to the net electrolyte fluxes. With ADH volume absorption in the colon is not so markedly reduced as in the small intestine (Table 1). The mean values of the reductions induced by ADH are $1.25 \mathrm{ml} / 10 \mathrm{~cm} \cdot \mathrm{h}$ in the jejunum, $0.73 \mathrm{ml} / 10 \mathrm{~cm} \cdot \mathrm{h}$ in the ileum, and $0.43 \mathrm{ml} /$ $10 \mathrm{~cm} \cdot \mathrm{h}$ in the colon.

Table 1 Volume absorption $(\mathrm{ml} / 10 \mathrm{~cm} \cdot \mathrm{h})$ in the jejunum, ileum, and colon of rats

\begin{tabular}{|c|c|c|c|c|c|}
\hline \multicolumn{2}{|l|}{ Jejunım } & \multicolumn{2}{|l|}{ Ileum } & \multicolumn{2}{|l|}{ Colon } \\
\hline $\begin{array}{l}\text { Without } \\
A D H\end{array}$ & $\begin{array}{l}\text { With } \\
A D H\end{array}$ & $\begin{array}{l}\text { Without } \\
A D H\end{array}$ & $\begin{array}{l}\text { With } \\
A D H\end{array}$ & $\begin{array}{l}\text { Without } \\
A D H\end{array}$ & $\begin{array}{l}\text { With } \\
A D H\end{array}$ \\
\hline $\begin{array}{l}-1.0 \\
-0.5 \\
-0.6 \\
-0.1 \\
-1.2 \\
-0.8 \\
-0.8 \\
-0.25\end{array}$ & $\begin{array}{l}+0.4 \\
+0.9 \\
+0.5 \\
+0.9 \\
+0.3 \\
+0.7 \\
+0.5 \\
+0.65\end{array}$ & $\begin{array}{l}-1.8 \\
-1.9 \\
-1.6 \\
-1.7 \\
-1.4 \\
-1.0 \\
-1.2 \\
-1.3\end{array}$ & $\begin{array}{l}-0.9 \\
-1.3 \\
-1.0 \\
-0.95 \\
-0.8 \\
-0.2 \\
-0.4 \\
-0.5\end{array}$ & $\begin{array}{l}-1.1 \\
-1.6 \\
-1.7 \\
-0.4 \\
-0.5 \\
-1.3 \\
-1.1 \\
-0.9\end{array}$ & $\begin{array}{l}-0.6 \\
-1.4 \\
-1.4 \\
+0.2 \\
+0.2 \\
-1.0 \\
-0.7 \\
-0.5\end{array}$ \\
\hline
\end{tabular}

- absorption, + secretion

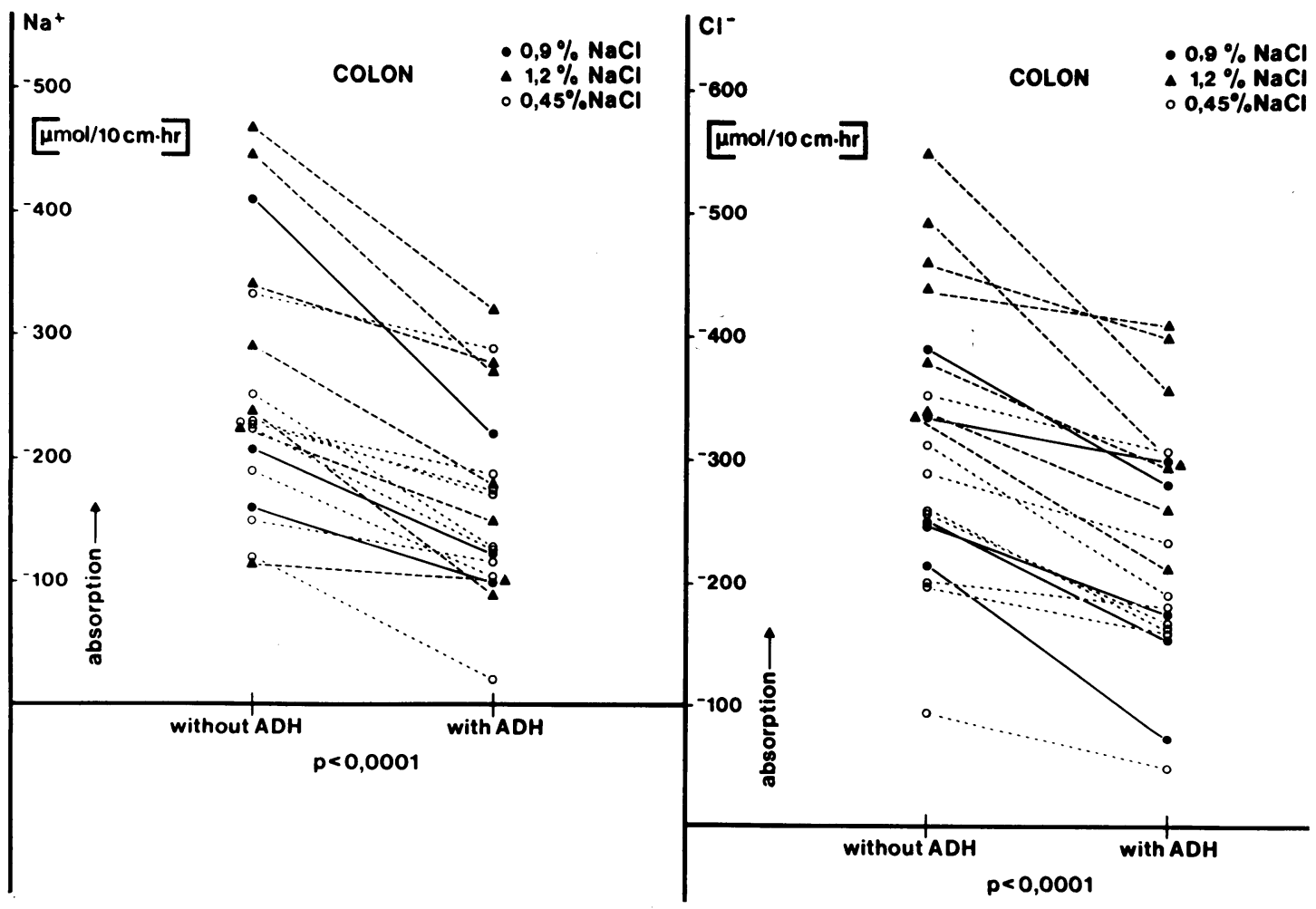

Fig. $2 \mathrm{Net} \mathrm{Na}^{+}$and net $\mathrm{Cl}^{-}$absorption in rat colon perfused with $0.45 \%, 0.9 \%, 1 \cdot 2 \% \mathrm{NaCl}$-solution. Individual experiments with and without intravenous application of $A D H$. 
EFFECT OF ADH ON NET FLUXES OF SODIUM AND WATER IN JEJUNUM

Regressional analysis of sodium on water shows that the sodium to water equivalent has not changed under the influence of ADH. Using a perfusion solution with $30 \mathrm{mM}$ glucose (total osmolality: $291 \pm 2 \mathrm{mosmol} / \mathrm{kg}$ ) the net volume and net sodium absorption in the proximal jejunum shows no significant changes with or without intravenous ADH:

\section{Control experiments}

$2.8 \pm 0.75 \mathrm{ml} / 10 \mathrm{~cm} \cdot \mathrm{h}$ resp. $359.0 \pm 79.3 \mu \mathrm{mol}$ $\mathrm{Na}^{+} / 10 \mathrm{~cm} \cdot \mathrm{h}$

\section{ADH experiments}

$2.7 \pm 0.68 \mathrm{ml} / 10 \mathrm{~cm} \cdot \mathrm{h} \quad$ resp. $370 \cdot 1 \pm 59.3 \mu \mathrm{mol}$ $\mathrm{Na}+10 \mathrm{~cm} \cdot \mathrm{h}$

The same results are obtainable when 3-0-methylglucose or amino-acids are used as substrates.

\section{EFFECT OF ADH ON UNIDIRECTIONAL}

\section{FLUXES OF SODIUM IN JEJUNUM}

The unidirectional fluxes of sodium are illustrated in Fig. 3. The flux from serosa to mucosa $\left(\Phi_{S} \rightarrow M\right)$ is statistically not different from the line of $45^{\circ}$ (dotted), which means that ADH has no influence on the efflux; on the other hand it distinctly reduces the influx $\left(\Phi_{M \rightarrow s}\right)$. The difference in the regression lines which correspond to the two unidirectional fluxes can be confirmed by statistics $(P=0.025)$. The reduction of the influx produced by $\mathrm{ADH}$ is equal to $35.3 \%$ as a mean value.

\section{EFFECT OF ADH ON UNIDIRECTIONAL}

FLUXES OF WATER IN JEJUNUM

The net volume fluxes without ADH $(2.7 \pm 0.45 \mathrm{ml} /$ $10 \mathrm{~cm} \cdot \mathrm{h}$ ) differ significantly from those with ADH
$(1.6 \pm 0.4 \mathrm{ml} / 10 \mathrm{~cm} \cdot \mathrm{h})$. This is due to a reduction in the unidirectional fluxes from mucosa to serosa (influx): the decrease is $32 \%$. The reduction of the water influx is in good agreement with the diminution of the sodium influx by $\mathrm{ADH}(35 \%) . \mathrm{H}_{2} \mathrm{O}$ efflux is diminished on the average, too, but this difference could not be confirmed statistically $(P>0 \cdot 1)$.

\section{ADH EFFECT UPON HEXOSE- AND UREA-}

TRANSPORT IN JEJUNUM

In further experiments, we examined the transport of fructose, glucose, and 3-0-methyl-glucose. Fructose is used as it is transported mainly passively in the intestine. 3-0-methyl-glucose, on the other hand, is nearly always actively transported without being metabolised in the intestinal wall as happens with glucose. It can be stated that ADH has no influence on the net transfer of the actively transported hexoses. However, the diffusion of urea from a solution containing $50 \mathrm{mmol} / \mathrm{l}$ towards the blood, as well as the absorption of fructose, are distinctly diminished (Table 2). The initial control values differ considerably from each other because each pair represents one animal.

\section{'HUMORAL TRANSMISSION' OF EFFECT OF ADH IN INTESTINE}

In the course of our experimental series, it became evident that a change of the test arrangementnamely, perfusion of the temporarily functional isolated segment of the small intestine in the 'open system' instead of the 'closed system'-produced a diminished effect of ADH. The described effect of vasopressin is always attainable. As to the quality, however, it is considerably less than during the experiments in the 'closed system'.

We observed that the effect of vasopressin, as to

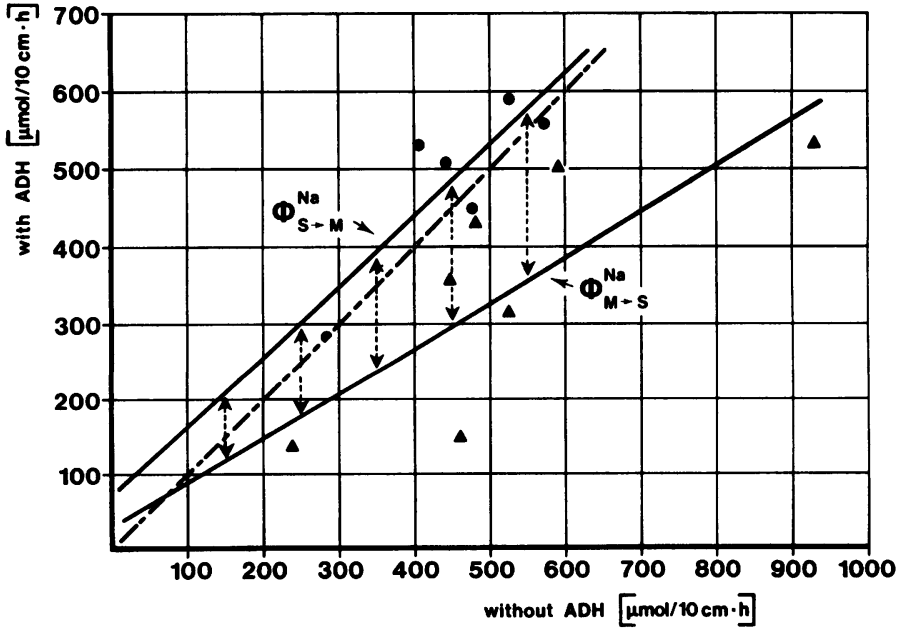

Fig. 3 Unidirectional $\mathrm{Na}^{+}-$fluxes with and without $A D H$. 
Table 2 Jejunum: net fructose and net urea transfer with and without $A D H$

\begin{tabular}{|c|c|c|c|}
\hline \multicolumn{2}{|c|}{$\begin{array}{l}\text { Fructose transfer rate } \\
(\mu \mathrm{mol} / 10 \mathrm{~cm} \cdot \mathrm{h})\end{array}$} & \multicolumn{2}{|c|}{$\begin{array}{l}\text { Urea transfer rate } \\
(\mu \mathrm{mol} / 10 \mathrm{~cm} \cdot h)\end{array}$} \\
\hline Without $A D H$ & With $A D H$ & Without $A D H$ & With $A D H$ \\
\hline $79 \cdot 5$ & $45 \cdot 5$ & 1231 & 930 \\
\hline $63 \cdot 8$ & $47 \cdot 7$ & 1015 & 783 \\
\hline $63 \cdot 5$ & 29.9 & 984 & 800 \\
\hline $40 \cdot 0$ & $21 \cdot 5$ & 730 & 495 \\
\hline $22 \cdot 8$ & $19 \cdot 7$ & 800 & 690 \\
\hline $54 \cdot 3$ & $26 \cdot 4$ & 804 & 695 \\
\hline
\end{tabular}

the quantity, is considerably less in the 'open system' than during the experiments in the 'closed system'. We therefore suspected that a substance was being discharged into the perfusion solution that caused the absorption changes. The volume absorption in the control experiment was $1.35 \mathrm{ml} / 10 \mathrm{~cm} \cdot \mathrm{h}$. This was followed by a perfusion experiment with the perfusate obtained after application of ADH $(0.35$ $\mathrm{ml} / 10 \mathrm{~cm} \cdot \mathrm{h}$ ). According to this diminution of volume absorption, the net sodium transport rate decreased from $145 \mu \mathrm{mol} / 10 \mathrm{~cm} \cdot \mathrm{h}$ to $15 \mu \mathrm{mol} /$ $10 \mathrm{~cm} \cdot \mathrm{h}$.

The absorption decrease or the change into a secretion under the influence of ADH can be imitated by the intraluminal application of cyclic AMP. Table 3 shows a comparison between the net sodium and water fluxes in the ileum of rats under control conditions, after addition of $10 \mathrm{mmol}$ cyclic AMP, to the perfusion solution $(0.9 \% \mathrm{NaCl})$ and after injecting $70 \mu \mathrm{U} / \mathrm{min} \cdot 100 \mathrm{~g}$ b.w. of $\mathrm{ADH}$ intravenously. The application of cyclic AMP always shows a diminished electrolyte and water absorption that is of about the same order as under ADH application.

Table 3 Effect of ADH and $10 \mathrm{mM} \mathrm{cAMP}$ on net volume and net $\mathrm{Na}^{+}$transport

\begin{tabular}{|c|c|c|c|c|c|}
\hline \multicolumn{2}{|c|}{$\begin{array}{l}\text { Control expts } \\
0.9 \% \mathrm{NaCl}\end{array}$} & \multicolumn{2}{|c|}{$\begin{array}{l}0.9 \% \mathrm{NaCl} \\
+10 \mathrm{mM} \mathrm{cAMP}\end{array}$} & \multicolumn{2}{|c|}{$0.9 \% \mathrm{NaCl}+A D H$} \\
\hline$\Phi_{N e t}^{N a}$ & $\Phi_{N e t}^{\mathrm{H}_{2} \mathrm{O}}$ & $\Phi_{N e t}^{N a}$ & $\Phi_{N e t}^{\mathrm{H}_{2} \mathrm{O}}$ & $\Phi_{N e t}^{N a}$ & $\Phi_{\mathrm{Net}}^{\mathrm{H}_{2} \mathrm{O}}$ \\
\hline $\begin{array}{l}-184 \\
-234 \\
-194 \\
-245 \\
-303 \\
-257 \\
-226 \\
-183\end{array}$ & $\begin{array}{l}-1.3 \\
-1.5 \\
-1.6 \\
-1.8 \\
-1.8 \\
-1.9 \\
-1.4 \\
-1.25\end{array}$ & $\begin{array}{l}-\quad 44 \\
-\quad 62 \\
-\quad 88 \\
-106 \\
-188 \\
-139 \\
+\quad 21 \\
-\quad 77\end{array}$ & $\begin{array}{l}-0.4 \\
-0.6 \\
-0.7 \\
-0.8 \\
-1.1 \\
-0.9 \\
+0.6 \\
-0.7\end{array}$ & $\begin{array}{l}-75 \\
+30\end{array}$ & $\begin{array}{l}-0.7 \\
+0.4\end{array}$ \\
\hline
\end{tabular}

The data mean $1 \mu \mathrm{mol} / 10 \mathrm{~cm} \cdot \mathrm{h}$ resp. $\mathrm{ml} / 10 \mathrm{~cm} \cdot \mathrm{h}$.

- absorption, + secretion. Each row of figures represents data from one animal.
Discussion

The present study confirms and completes our previous results concerning the effect of physiological concentrations of ADH in circulating blood on the intestinal transport mechanisms. In the rat, considerable diminution of the electrolyte and water transport by vasopressin takes place, not only in the small intestine but also in the colon. With regard to the net volume and electrolyte absorption there seems to be an oral-aboral gradient of vasopressin effectiveness. Under isotonic test conditions, water absorption in the jejunum changes into secretion, while in the ileum absorption is considerably diminished. In the colon the effect of ADH is still present, but much smaller than in the small bowel. The unidirectional fluxes are influenced in both directions, toward lumen and blood, the influx being more diminished than the efflux.

Our results show that ADH reduces the intestinal absorption of both water and electrolytes. So it may be supposed that the electrolyte transfer changes are the primary step.

The relatively high transfer rate of actively absorbed glucose and 3-0-methyl-glucose might mask changes of the passive transport components. In the case of passive transported molecules, such as fructose and urea, the disappearance rates for both substrates from the intestinal lumen are decreased by ADH. These findings are in contradiction to the results of Soergel et al. (1968): they could not observe in man any changes of the transport rates of glucose, xylose, and urea under the influence of ADH.

According to the equation for the transepithelial net transport of a solute (Ullrich, 1973), it can be derived that the transfer rates of fructose or urea respectively depend directly on the volume flow (solvent drag). This equation is also suitable for actively transported substrates such as glucose or 3-0-methyl-glucose. An enhanced active substrate transport (influx) can compensate for the opposite effect of 'solvent drag' (diminished influx). This might explain the fact that the transfer of glucose or 3-0-methyl-glucose is not changed under the influence of ADH.

As for all other epithelial systems, ADH produces an effect on the intestine only if it is administered from the serosal side. But it affects the epithelial cell always only at the mucosal and apical side. In different tissues it could be shown that the vasopressin effect is mediated by cyclic AMP (Orloff and Handler, 1967; Mendoza et al., 1970; Robison et al., 1971). In the kidney of mammals it is assumed that ADH stimulates the formation of cyclic AMP, which increases the permeability, for example, for water and urea by changing the physicochemical properties of 
the membranes. The absorption decrease or the change into secretion, as shown above, points to the fact that a substance was discharged into the perfusion solution that causes the absorption changes, possibly cAMP. The identification of this substance in the perfusate as well as experiments about the adenylcyclase activity in different intestinal segments are envisaged.

The effect of cyclic AMP on the small intestinal mucosa has been described by Field et al. (1976), who examined in vitro the ileum mucosa of rabbits: it reduces the net sodium flux due to a decrease of the unidirectional mucosal-serosal-flux. Moreover, the absorption of chloride changes under cAMP into a secretion. This is presumably caused by an active $\mathrm{Cl}^{-}$-secretion. The changes of $\mathrm{Cl}^{-}$-absorption in our experiments do not differ widely from the net sodium movements, which means that an isolated $\mathrm{Cl}^{-}$secretion cannot necessarily be inferred from this.

As in the presence of glucose and amino-acids ADH does not show any significant change of net electrolyte and water transport, there must exist two mutually independent transport pathways for sodium and water, of which one is influenced by ADH and cAMP. The sodium transport stimulated by actively transported hexoses or amino-acids remains unchanged. Provided that ADH increases the permeability in luminal cell membranes, assuming that the active electrolyte transport remains unchanged, the underlying mechanism might be discussed by means of the three-chamber-model (Fig. 4) (Curran, 1960; Dennhardt and Haberich, 1972). The active sodium transport by membrane $\mathbf{A}$ into the second chamber occurs uninfluenced, as does the isotonic equivalent water influx. Normally, an accumulation of sodium and water in chamber 2 results from the different reflexion coefficients of membranes $A$ and $B\left(\sigma_{A}>\right.$ $\left.\sigma_{B}\right)$, where the immediate result is an increase of the hydrostatic pressure and a flow into chamber 3 . If there is a partial leak in membrane $\mathrm{A}$, for example, one part of the electrolytes in chamber 2 with a corresponding volume will flow back to chamber 1 . This interpretation agrees with the unidirectional flux measurements: $\Phi_{\mathrm{M} \rightarrow \mathrm{s}}^{\mathrm{Na}}$ is always decreased in the presence of ADH. An additional shunt from chamber 3 to chamber 1 , which would decrease the net transport, cannot be excluded. Considering the different ADH effects in various intestinal segments, the decreased sodium absorption is explainable: in the whole intestine the active sodium transport is not altered under the influence of ADH, but the passive sodium movement is. As this passive component is markedly different in various intestinal segmentsmost in the jejunum, least in the colon-the oralaboral effect of ADH in the intestine can be explained in this way. The decreased transport rates of fructose

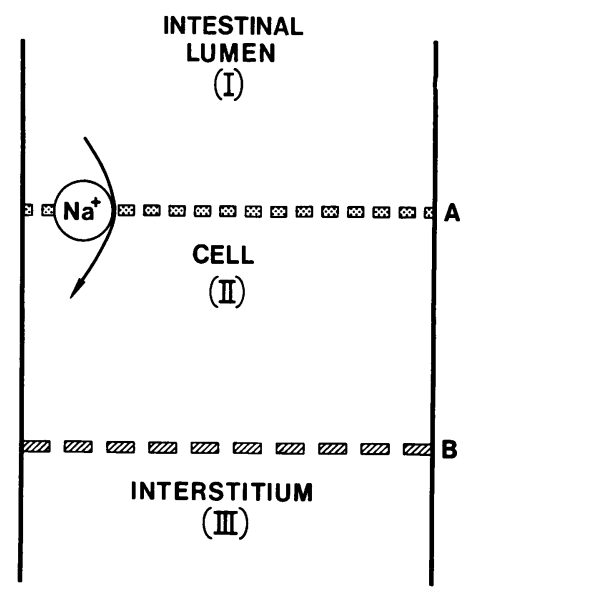

Fig. 4 Two-membrane-model. For further details see text.

and urea can be explained by the influence of the diminished volume flow (solvent drag).

\section{References}

Aziz, O. (1969). Versuche am gekreuzten Kreislauf mit wachen Ratten II. Endogene Sekretion und Plasmakonzentration von ADH. Pflügers Archiv, 311, 355-372.

Bonjour, J. P., and Malvin, R. L. (1970). Plasma concentrations of ADH in conscious and anaesthetised dogs. American Journal of Physiology, 218, 1128-1132.

Curran, P. F. (1960). Na, Cl, and water transport by rat ileum in vitro. Journal of General Physiology, 43, 1137-1148.

Curran, P. F., and Solomon, A. K. (1957). Ion and water fluxes in the ileum of rats. Journal of General Physiology, 41, 143-168.

Dennhardt, R., and Haberich, F. J. (1972). Wirkung von ADH auf den Netto-Wasser und Elektrolyttransport am Dünndarm wacher Ratten. Pfügers Archiv, 334, 74-84.

Dennhardt, R., and Haberich, F. J. (1973). Die Wirkung aktiv transportierter Zucker auf den Natrium-, Kaliumund Volumentransport am Jejunum und Ileum der Ratte. Pflügers Archiv, 345, 221-236.

Field, M., Brasitus, T. A., Sheerin, H. E., and Kimberg, D. V. (1976). Role of cyclic nucleotides in the regulation of intestinal ion transport. In Intestinal Ion Transport, pp. 233245. Edited by J. W. L. Robinson. MTP Press: Lancaster.

Haberich, F. J., Herzer, R., Aziz, O., and Dennhardt, R. (1968). Resorptions- und Sekretionsstudien am Darm. I. Technik der extrakorporalen Perfusion beliebiger, vorübergehend funktionell isolierter Darmabschnitte an der wachen Ratte. Zeitschrift für die Gesamte Experimentelle Medizin, 148, 223-237.

Hays, R. M., and Leaf, A. (1962). Studies on the movement of water through the isolated toad bladder and its modifications by vasopressin. Journal of General Physiology, 45, 905-919.

Mendoza, S. A., Handler, J. S., and Orloff, J. (1970). Effect of inhibitors of sodium transport on response of toad bladder to ADH and cyclic AMP. American Journal of Physiology, 219, 1440-1445.

Orloff, J., and Handler, J. (1967). The role of adenosine 3', $5^{\prime}$-phosphate in the action of antidiuretic hormone. American Journal of Medicine, 42, 757-768.

Robison, G. A., Butcher, R. W., and Sutherland, E. W. 
(1971). Cyclic $A M P$, pp. 338-345. Academic Press: New York.

Soergel, K. H., Whalen, G. E., Harris, J. A., and Geenen, J. E. (1968). Effect of antidiuretic hormone on human small intestinal water and solute transport. Journal of Clinical Investigation, 47, 1071-1082.

Ullrich, K. J. (1973). Handbook of Physiology, Section 8, Renal Physiology, pp. 377-414. Edited by J. Orloff and R. W. Berliner. American Physiological Society: Washington D.C.

\section{Appendix}

As a basis for the mathematical treatment, we assume a two-compartment system. We have a '-phase (lumen) and a "-phase (plasma) separated by a membrane system (intestine). $A$ substance $M$ together with one of its radioactive isotopes $M^{x}$ is soluted.

Investigations by Curran and Solomon (1957) serve as a basis for the calculation of the fluxes, but had to be generalised for our purpose.

The following symbols are used:

In the '-phase:

$\mathbf{M}^{\prime}$ : total amount of the soluted substance

$\left[\mathrm{M}^{\prime}\right]$ : concentration of the soluted substance

$\mathbf{M}^{\mathbf{x}^{\prime}}$ : total rate of activity $(\mathrm{cpm})$

$\left[\mathrm{M}^{\mathbf{x}}\right]$ : activity/ml

$\left[\mathrm{m}^{\mathrm{x}^{\prime}}\right.$ ]: specific activity $(\mathrm{cpm} / \mathrm{mM})$

$\Phi_{M}^{\prime}$ : flux from 'to " (mmol/min)

Analogous symbols are applicable to the "-phase.

Provided $\Phi_{M}^{\prime}$ is proportional to $\left[\mathrm{M}^{\prime}\right]$ we have

$\begin{aligned} \Phi_{M}^{\prime} & =k^{\prime}\left[M^{\prime}\right] \\ \text { and } \Phi_{M}^{M} & =k^{\prime \prime}\left[M^{\prime \prime}\right]\end{aligned}$

The total change of $\mathbf{M}^{\prime}$ in the compartment is:

$$
\frac{\mathrm{dM}^{\prime}}{\mathrm{dt}}=-\Phi_{\mathrm{M}}^{\prime}+\Phi_{\mathrm{M}}^{\prime}
$$

The same equation can be applied to the change of Mx.

$$
\begin{aligned}
& \frac{\mathrm{dM}^{\mathrm{x}^{\prime}}}{\mathrm{dt}}=-\Phi_{\mathrm{M}}^{\prime}+\Phi_{\mathrm{M}}^{*} \mathrm{x} \\
& =-\Phi_{M}^{\prime}\left[\mathrm{m}^{\mathrm{x}^{\prime}}\right]+\Phi_{M}^{*}\left[\mathrm{~m}^{\mathrm{x}^{\prime}}\right]
\end{aligned}
$$

$\mathbf{M}^{\mathbf{x}^{\prime}}$ can be written as:

$$
\mathbf{M}^{\mathbf{x}^{\prime}}=\left[\mathbf{M}^{\mathbf{x}^{\prime}}\right] \mathbf{V}^{\prime}
$$

$\mathrm{V}^{\prime}$ being the volume in the '-phase.

[ $\left.\mathrm{mx}^{\prime}\right]$ is derived from the equation:

$$
\left[\mathrm{M}^{\mathrm{x}^{\prime}}\right]=\left[\mathrm{m}^{\mathrm{x}^{\prime}}\right]\left[\mathrm{M}^{\prime}\right]
$$

For further calculation the following approximations were made:

1. The plasma concentration of $M$ is constant

2. $\left[\mathrm{m}^{\mathrm{x}^{\prime \prime}}\right]$ is negligibly small compared with $\left[\mathrm{m}^{\mathrm{x}^{\prime}}\right]$

3. The volume changes may be assumed to be linear in time:

$$
V^{\prime}=V o^{\prime}(1-\lambda t)
$$

$V^{\prime}$ being the volume at time $t=0$

On the basis of these approximations we can solve the equations for $k^{\prime}$ :

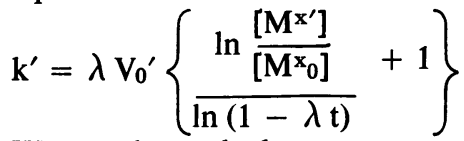

We can then calculate an average value of

Using (3) we may derive

$$
\Phi_{\mathrm{M}}^{\prime}=\mathrm{k}^{\prime}\left[\mathrm{M}^{\prime}\right]
$$

$$
\left[\bar{M}^{\prime}\right]=\left(\left[\mathbf{M}^{\prime}\right]+\left[\mathbf{M o}^{\prime}\right]\right) / 2
$$

Therefore we obtain from (3) and (4)

$$
\Phi_{\mathbf{M}^{\prime}}=\mathrm{k}^{\prime}\left[\overline{\mathbf{M}}^{\prime}\right]
$$

The opposite unidirectional flux results from

$\Phi_{M}^{*}=\left(k^{\prime}-\lambda V_{0}\right)\left\{\frac{\left[M^{\prime}\right]\left[M_{0}^{x^{\prime}}\right]-\left[M_{0}^{\prime}\right]\left[M^{x^{\prime}}\right]}{\left[M_{0}^{x^{\prime}}\right]-\left[M^{x^{\prime}}\right]}\right\}$

All the quantities on the right side of (3), (4), (5) are measurable. Therefore the average net flux may be derived:

$$
\bar{\Phi}_{M}=\bar{\Phi}_{M}^{\prime}-\bar{\Phi}_{M}^{\prime}
$$

